\title{
Synthesis of polyphthalaldehyde-based block copolymers: utilization of a thermo- sacrificial segment for an easy access to fine-tuned poly(3-hexylthiophene) nanostructured films
}

\section{Supporting Information:}

Representative synthesis of alkyne-terminated P3HT (HCEC-P3HT) by GRIM. In a previously flamed and dried round-bottom flask, 2,5-dibromo-3-hexylthiophene $(0.6 \mathrm{~mL}$, $2.8 \mathrm{mmol}$ ) was dissolved in $13 \mathrm{~mL}$ of THF. To this solution was added isopropylmagnesium chloride $(1.4 \mathrm{~mL}, 2.8 \mathrm{mmol})$ to form the Grignard reagent. After $30 \mathrm{~min}$ at $0^{\circ} \mathrm{C}$, the solution was transferred by cannula and under nitrogen to a suspension of $\mathrm{Ni}(\mathrm{dppp}) \mathrm{Cl}_{2}(16.8 \mathrm{mg}$, $0.03 \mathrm{mmol})$ dispersed in THF $(7 \mathrm{ml})$. After $1 \mathrm{~h}$ at $0^{\circ} \mathrm{C}$, the iced bath was removed to slowly let the medium warming up to ambient temperature. Once at r.t., $15 \mathrm{~mL}$ of anhydrous THF were added to the mixture. After complete solubilization, $0.5 \mathrm{~mL}$ of ethynylmagnesium chloride $\left(0.25 \mathrm{mmol}, 8 \mathrm{eq} / \mathrm{Ni}(\mathrm{dppp}) \mathrm{Cl}_{2}\right)$ was introduced to the reaction flask. After $30 \mathrm{~min}$, the polymer was precipitated in cold methanol. To avoid possible end-group alteration, ${ }^{57}$ no Soxhlet extraction was performed. The as-obtained solid was then isolated by filtration from the methanol fraction and directly washed with an excess of methanol, acetone and hexane to remove residual metal salts, unreacted monomers and oligomers. Yield $=46 \%$. ${ }^{1} \mathrm{H}$ NMR (500 MHz, $\left.\mathrm{CDCl}_{3}, \delta \mathrm{ppm}\right): 6.98(\mathrm{~s}, 1 \mathrm{H}), 3.53(\mathrm{~s}, 1 \mathrm{H}), 2.80(\mathrm{t}, 2 \mathrm{H}), 1.72(\mathrm{~m}, 2 \mathrm{H}), 1.40-1.30$ (m, 6H) 0.9 (s, 3H); SEC: $\mathrm{M}_{\mathrm{n}}=20300 \mathrm{~g} \mathrm{~mol}^{-1}, \bigoplus_{\mathrm{M}}=1.20$; MALDI-ToF: $\mathrm{m} / z: 16733$ (calcd: 16733, DP of 100, alkyne / Br end-groups).

Representative synthesis of azido-terminated PPA $\left(N_{3}-P P A\right)$. In a glovebox, a previously flamed-dried round bottom flask (of $25 \mathrm{~mL}$ ) was charged with the PA monomer (500 mg, $\left.3.71 \times 10^{-3} \mathrm{~mol}\right)$ solubilized in $10 \mathrm{~g}$ of dried dichloromethane $(\mathrm{DCM})$. The flask was then 
sealed with a septum and immersed in a $-85^{\circ} \mathrm{C}$ cooling bath out of the box. Then, in a glovebox, the $\mathrm{P}_{1}$-t -Bu catalyst $\left(3.6 \mathrm{mg}, 1.54 \times 10^{-5} \mathrm{~mol}\right)$ and the 11 -azido-1-undecanol initiator $\left(6.60 \mathrm{mg}, 3.09 \times 10^{-5} \mathrm{~mol}\right)$ were solubilized by $300 \mu \mathrm{L}$ of DCM. In a cold room thermostatized at $5^{\circ} \mathrm{C}$, the activated initiator solution was transferred to the monomer one always kept at $85^{\circ} \mathrm{C}$. After 15 minutes, a DCM solution of 2-bromoethyl isocyanate quenching agent (7.0 $\mathrm{mg}, 4.67 \times 10^{-5} \mathrm{~mol}$ in $300 \mu \mathrm{L}$ of $\left.\mathrm{DCM}\right)$ was injected to the polymerization medium. The solution was kept under agitation at $-85^{\circ} \mathrm{C}$ for an extra 30 min prior to its precipitation into cold methanol. The azido-terminated polyphthalaldehyde was then filtered out and dried at r.t. until constant weight. Yield $=87 \%$; SEC: $\mathrm{Mn}=16800 \mathrm{~g} \mathrm{~mol}^{-1}, \bigoplus_{\mathrm{M}}=1.42 ;$ MALDI-ToF: m/z: 17153 (calcd: 17153, DP of 125, $\mathrm{N}_{3} / \mathrm{Br}$ end-groups)

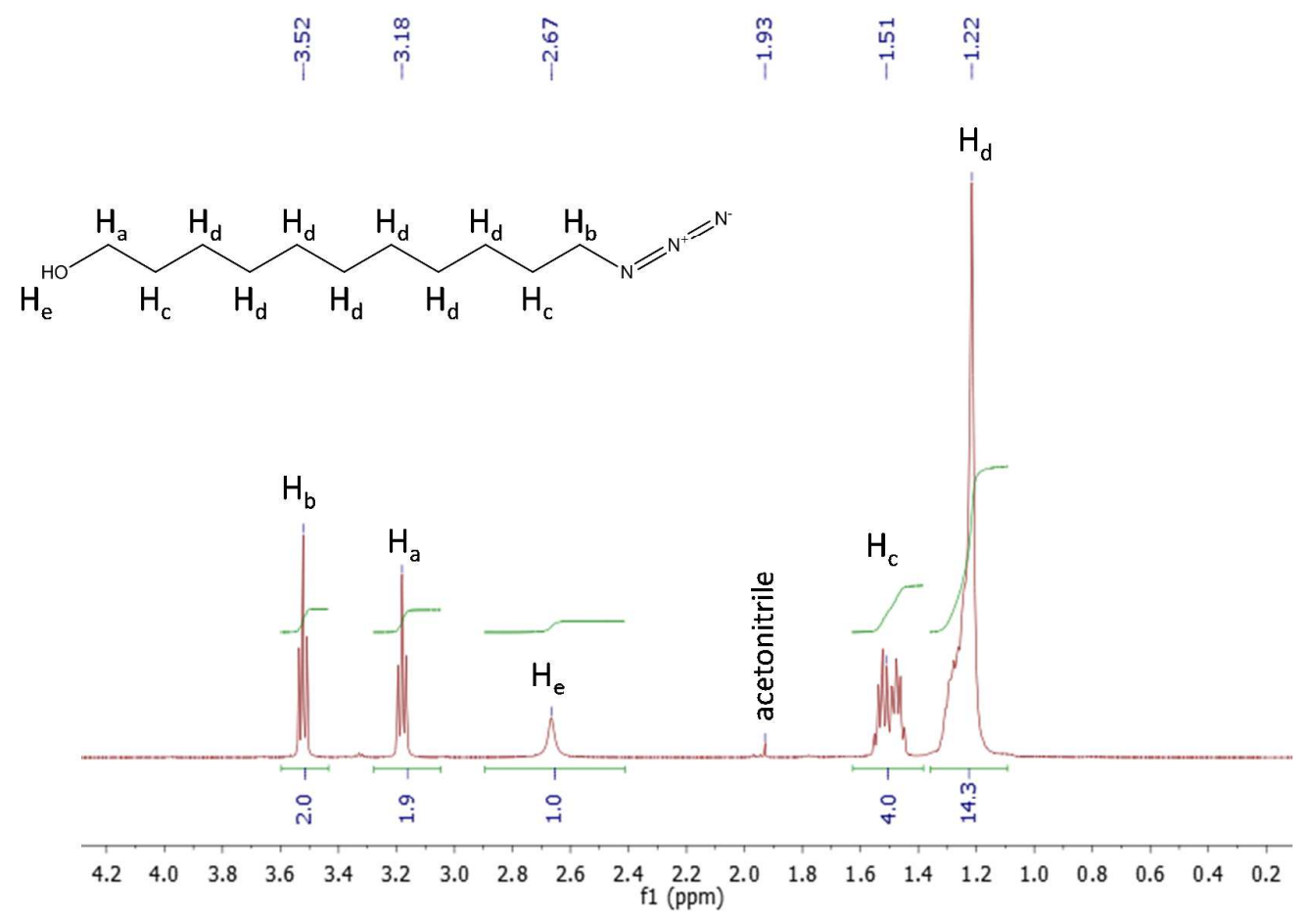

Figure $S 1{ }^{1}$ H NMR spectrum of 11-azido-1-undecanol 


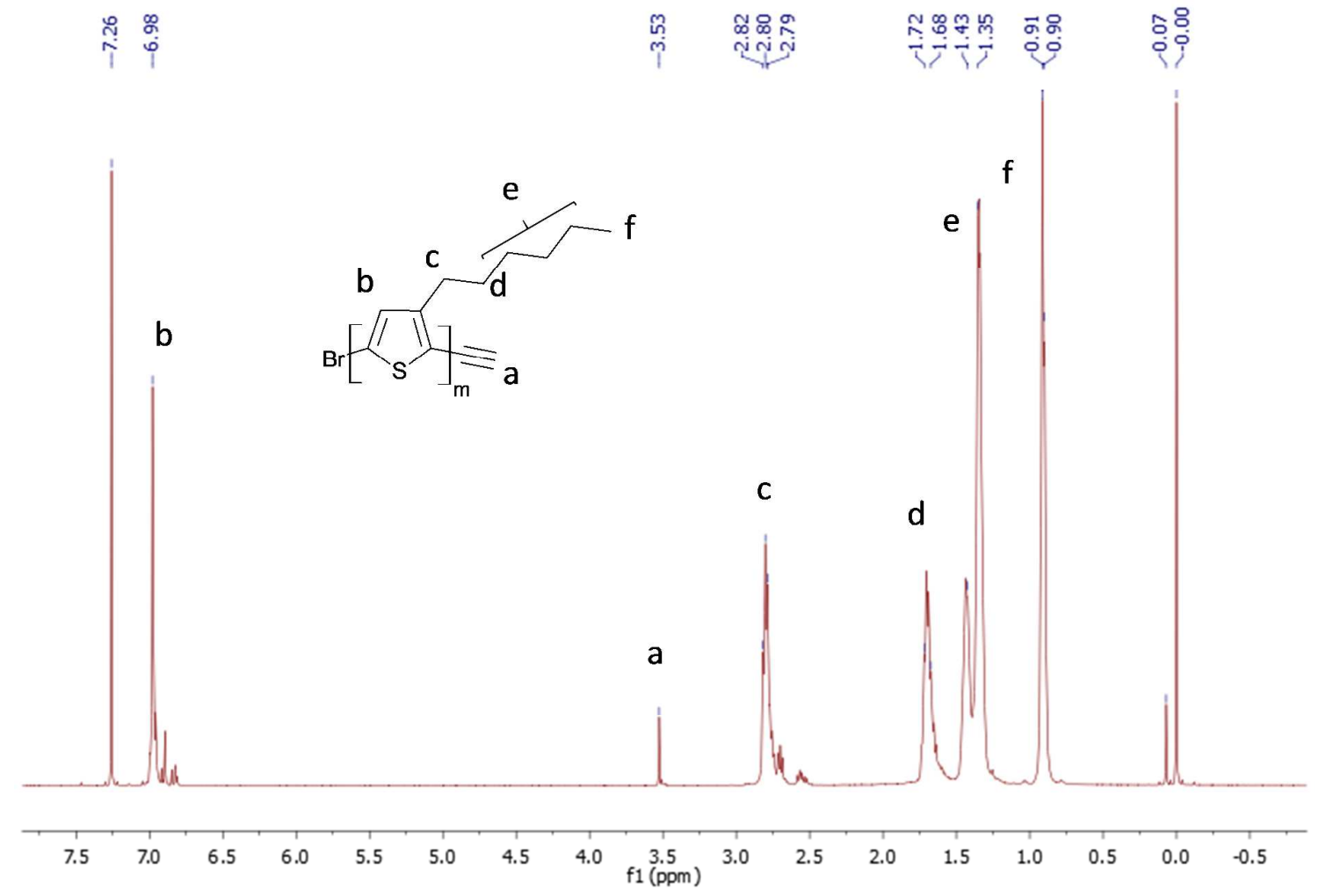

Figure $S 2{ }^{1} H$ NMR P3HT 27 


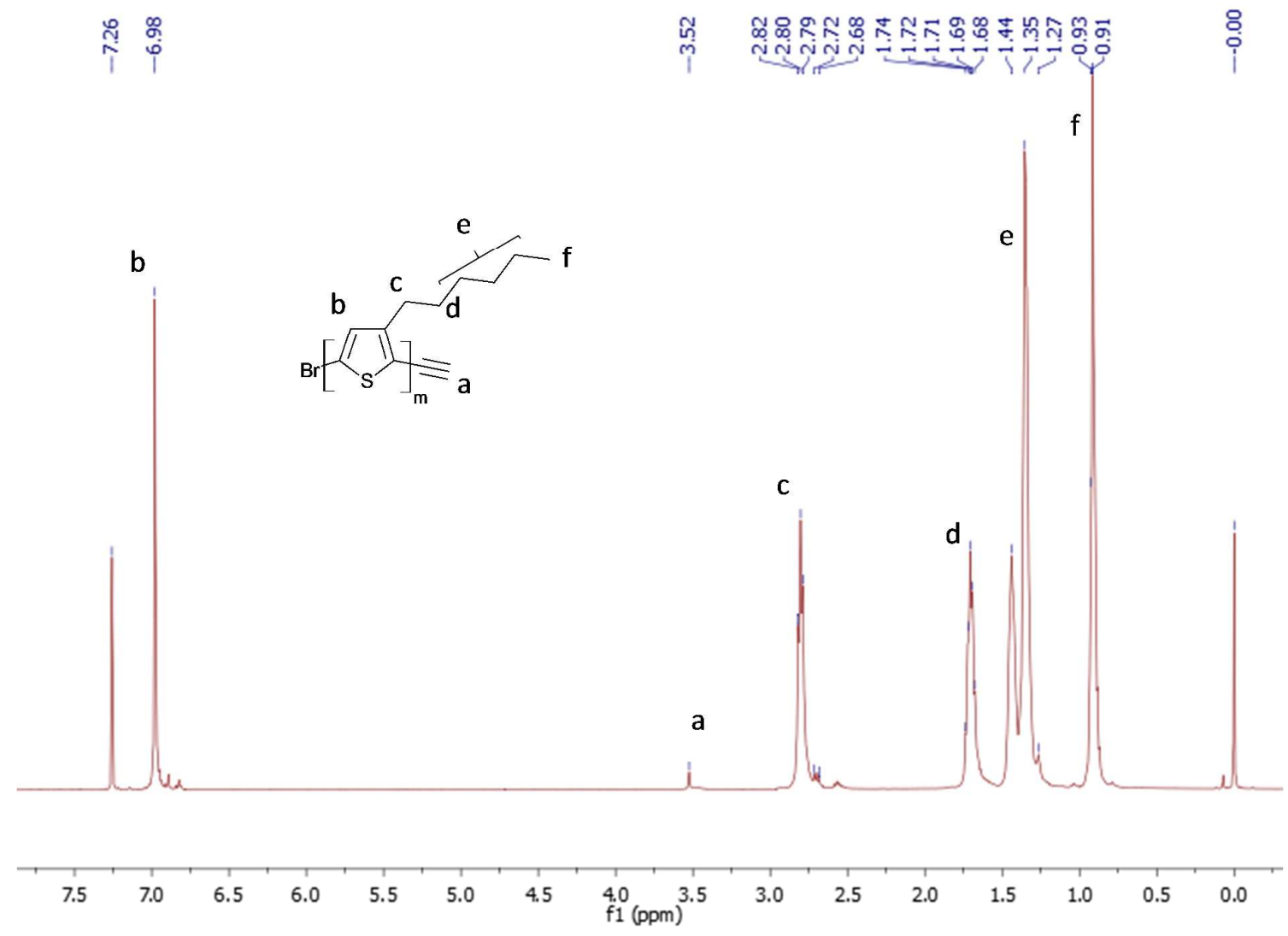

Figure $S 3{ }^{1} \mathrm{H} N M R \mathrm{P} 3 \mathrm{HT}_{54}$ 


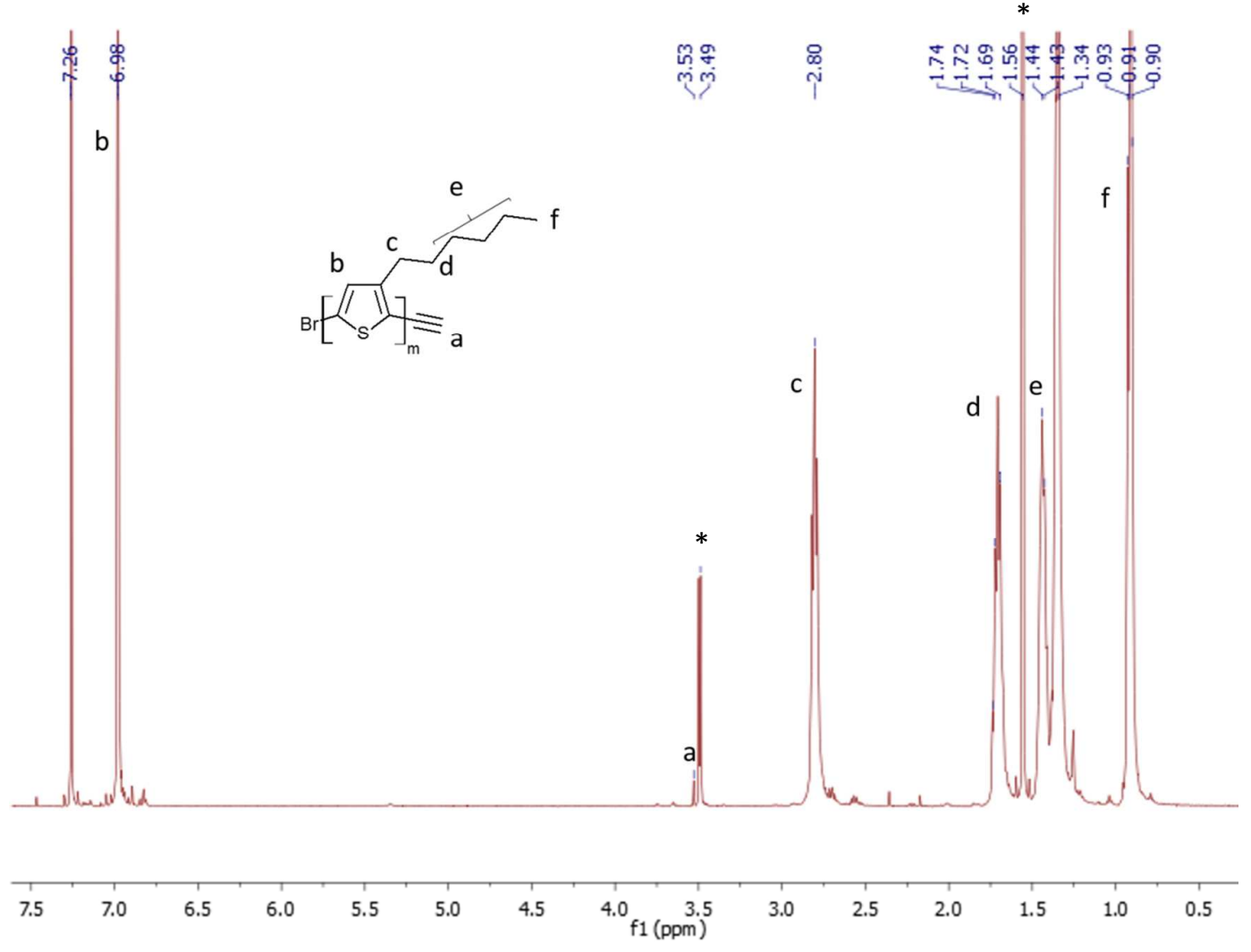

Figure $S 4{ }^{1} H$ NMR P3HT 78 (* refer to methanol signals)

A

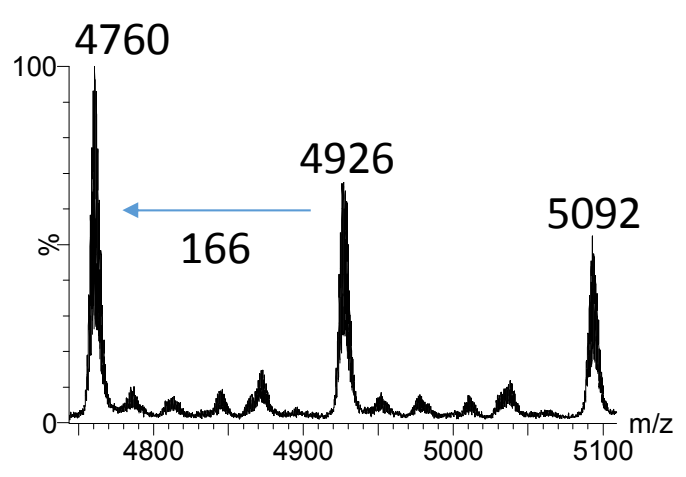

B

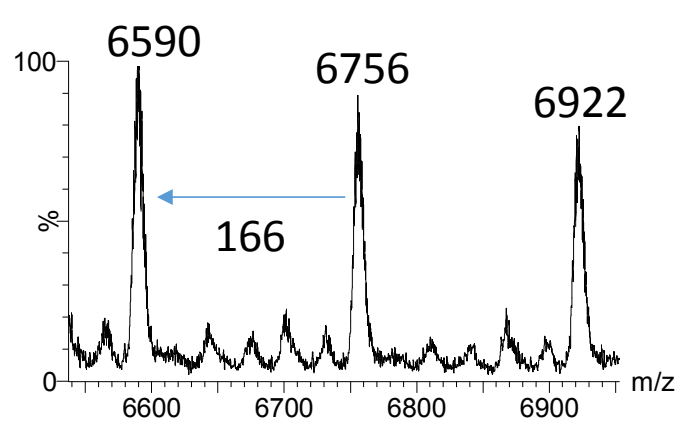

Figure S5 MALDI-(+)-ToF-MS spectrum of P3HT A and B; simulation of 30 monomer units, $\mathrm{C}_{300} \mathrm{H}_{420} \mathrm{~S}_{30} \mathrm{BrC}_{2} \mathrm{H}: 5092 \mathrm{~g} \mathrm{~mol}^{-1}$; simulation of 40 monomer units, $\mathrm{C}_{400} \mathrm{H}_{560} \mathrm{~S}_{40} \mathrm{BrC}_{2} \mathrm{H}: 6756$ $\mathrm{g} \mathrm{mol}^{-1}$ 

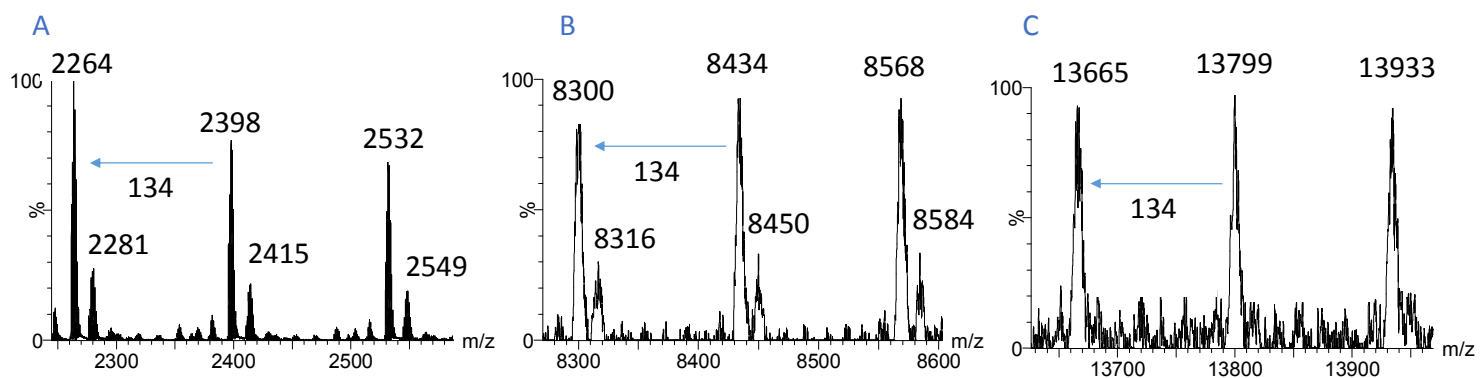

Figure S6 MALDI-(+)-ToF-MS spectrum of PPA $A_{25}(A), P P A_{70}(B), P P A_{125}(C)$; simulations of 15 monomer units, $\mathrm{C}_{120} \mathrm{H}_{90} \mathrm{O}_{30} \mathrm{C}_{11} \mathrm{H}_{22} \mathrm{ON}_{3} \mathrm{C}_{3} \mathrm{H}_{5} \mathrm{ONBrNa}: 2398 \mathrm{~g} \mathrm{~mol}^{-1}$ and $\mathrm{C}_{120} \mathrm{H}_{90} \mathrm{O}_{30} \mathrm{C}_{11} \mathrm{H}_{22} \mathrm{ON}_{3} \mathrm{C}_{3} \mathrm{H}_{5} \mathrm{ONBrK}$ : $2415 \mathrm{~g} \mathrm{~mol}^{-1}$; simulations 60 monomer units, $\mathrm{C}_{480} \mathrm{H}_{360} \mathrm{O}_{120} \mathrm{C}_{11} \mathrm{H}_{22} \mathrm{ON}_{3} \mathrm{C}_{3} \mathrm{H}_{5} \mathrm{ONBrNa}: 8434 \mathrm{~g} \mathrm{~mol}^{-1}$ and $\mathrm{C}_{480} \mathrm{H}_{360} \mathrm{O}_{120} \mathrm{C}_{11} \mathrm{H}_{22} \mathrm{ON}_{3} \mathrm{C}_{3} \mathrm{H}_{5} \mathrm{ONBrK}$ : $8450 \mathrm{~g} \mathrm{~mol}^{-1}$; simulations 100 monomer units, $\mathrm{C}_{800} \mathrm{H}_{600} \mathrm{O}_{200} \mathrm{C}_{11} \mathrm{H}_{22} \mathrm{ON}_{3} \mathrm{C}_{3} \mathrm{H}_{5} \mathrm{ONBrNa}$ : $13799 \mathrm{~g} \mathrm{~mol}^{-1}$.
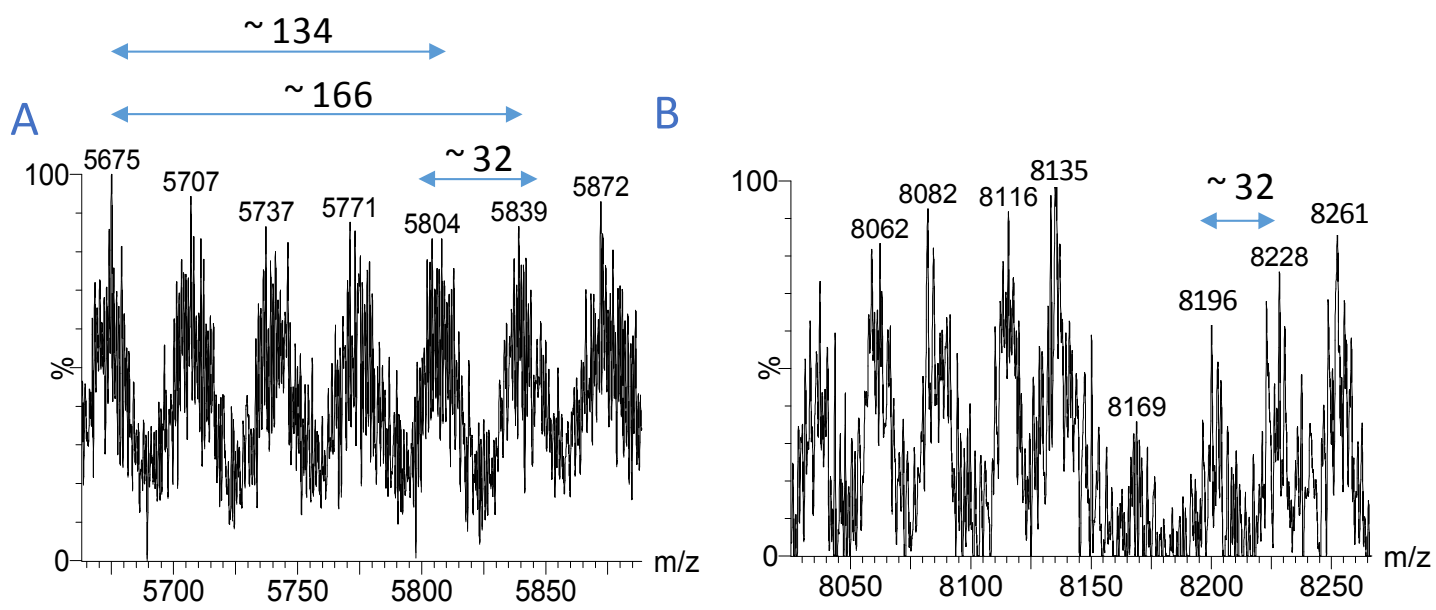

Figure S7 MALDI-(+)-ToF-MS analysis of $P 3 H_{27}-b-P P A_{25}$ and $P 3 H_{54}-b-P P A_{70}$
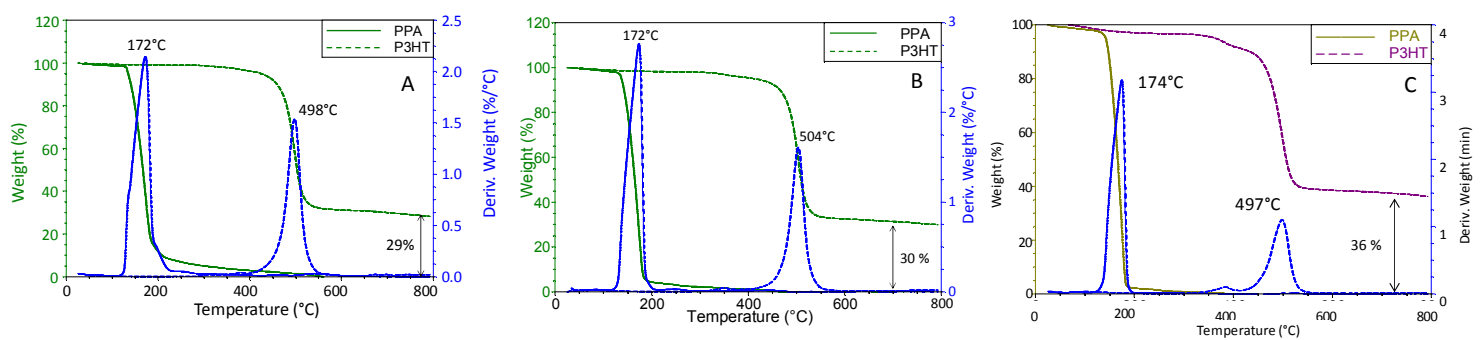

Figure S8 TGA of P3HT 27 and PPA $25, P_{3 H} T_{54}$ and $P P A_{70}(B)$ and $P 3 H T_{78}$ and $P P A_{125}(C)$. 

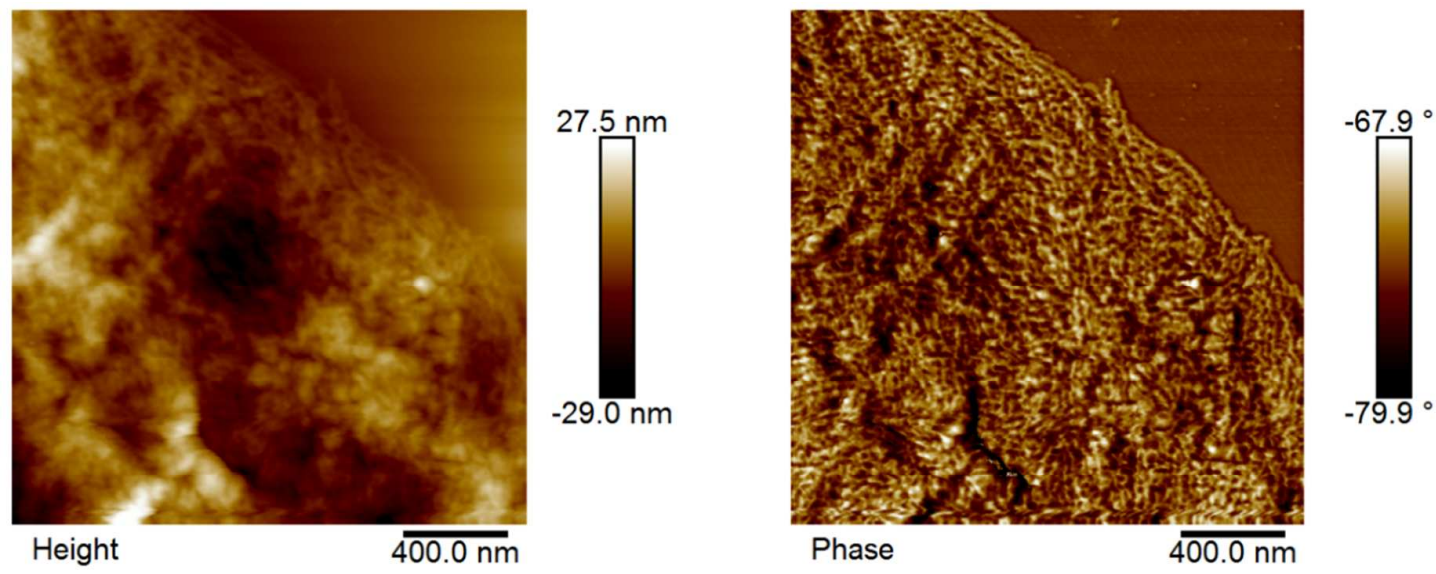

Figure S9 TM-AFM height (left) and phase (right) images of a thin film of P3HT 78 (13000 g. $\mathrm{mol}^{-1}$ ). 